\title{
Serologische Verlaufstests bei Zöliakie unnötig
}

\author{
Wird bei Kindern eine Zöliakie festgestellt, müssen sie auf eine glutenfreie Diät eingestellt \\ werden. In der Folge sind serologische Verlaufsuntersuchungen offenbar überflüssig.
}

_ Die Zöliakie wird serologisch durch erhöhte Antikörper gegen Endomysium und/oder Transglutaminase 2 nachgewiesen. Im Zweifelsfall muss eine Dünndarmbiopsie genommen werden. Widersprüchlich wird hingegen die Frage gesehen, inwieweit man nach der Einstellung auf eine glutenfreie Diät Ernährungsdefizite und Schilddrüsenfunktion serologisch kontrollieren sollte.

In einer niederländischen Studie wurde daher der Einfluss einer solchen Diät bei Kindern mit Zöliakie untersucht. Zwischen 2009 und 2015 wurden insgesamt 182 Patienten rekrutiert. Bei allen wurden regelmäßig die Serumwerte von Hämoglobin, Ferritin, Folat, Vitamin $\mathrm{B}_{12}$, Kalzium, Vitamin D und TSH bestimmt, und zwar zum Zeitpunkt der Diagnose, nach 9-18 Monaten, nach 1,52,5 Jahren sowie nach 2,5-3,5 Jahren.
Zum Zeitpunkt der Diagnose hatten 28\% der Kinder ein Eisendefizit und 9\% eine Anämie. Der Serumspiegel von Folat war bei $14 \%$ erniedrigt, der von Vitamin $B_{12}$ bei $1 \%$ und der von Vitamin D bei $27 \%$. Bei keinem Patienten konnte eine Hypokalzämie oder eine Schilddrüsendysfunktion nachgewiesen werden.

Bei den Nachuntersuchungen über drei Jahre zeigte sich eine Verbesserung. Nur noch $8 \%$ der Kinder hatten einen Eisenmangel, $2 \%$ eine Eisenmangelanämie und 3\% einen Folatmangel. Allerdings bestand noch bei $25 \%$ ein Vitamin-D-Defizit. Ein Vitamin $\mathrm{B}_{12}$-Mangel, eine Hypokalzämie oder eine Schilddrüsenfunktionsstörung bestand bei keinem Patienten.

- Wessels MM, van Veen II, Vriezinga SL et al. Complementary serologic investigations in children with celiac disease is unnessessary during follow-up. J Pediatr. 2016;169:55-60

\begin{abstract}
KOMMENTAR
Die Autoren plädieren für einen Verzicht auf die komplementären Serumuntersuchungen, um Kosten zu verringern und auch die psychische Belastung zu vermeiden. Die wieder einmal beobachtete Persistenz eines bestehenden Vitamin-D-Defizits sehen sie eher als Folge eines allgemeinen Mangels in der Normalbevölkerung. Eine generelle Vitamin- $D$ Langzeitsupplementierung befürworten sie aber dennoch. Serologische Verlaufsuntersuchungen empfehlen sie nur bei spezifischen Indikationen wie Wachstums- oder Gewichtsregression - oder bei einer auffälligen klinischen Symptomatik, etwa einer kontinuierlichen Müdigkeit.

Es bleibt zu hoffen, dass die Studie dazu beiträgt, die verschiedenen, leider kontroversen Leitlinien zahlreicher Gesellschaften und Kommissionen zu vereinheitlichen.
\end{abstract}

Prof. em. Dr. med. Dr. h. c. D. Reinhardt

\section{Kokain-Loch im Gaumen}

Ein 44-jähriger Mann mit langjähriger Anamnese eines Kokain-Abusus litt seit einem Jahr unter Kopfschmerzen und einem fortschreitenden Frontalhirnsyndrom. Bei der Untersuchung zeigten sich eine Ophthalmoparese, leichte rechtsseitige Pyramidenzeichen und ein Defekt in der Mittellinie des harten Gaumens (Abb. A). Im CT erkannte man ausgedehnte Destruktionen knöcherner und knorpeliger Strukturen der Nasenhöhle (Abb. B), in der Kernspintomografie ein Ödem des Frontallappens mit intensiver meningealer Kontrastverstärkung (Abb. C, T2-Gewichtung). Im Labor zeigten sich antineutrophile zytoplasmatische Antikörper
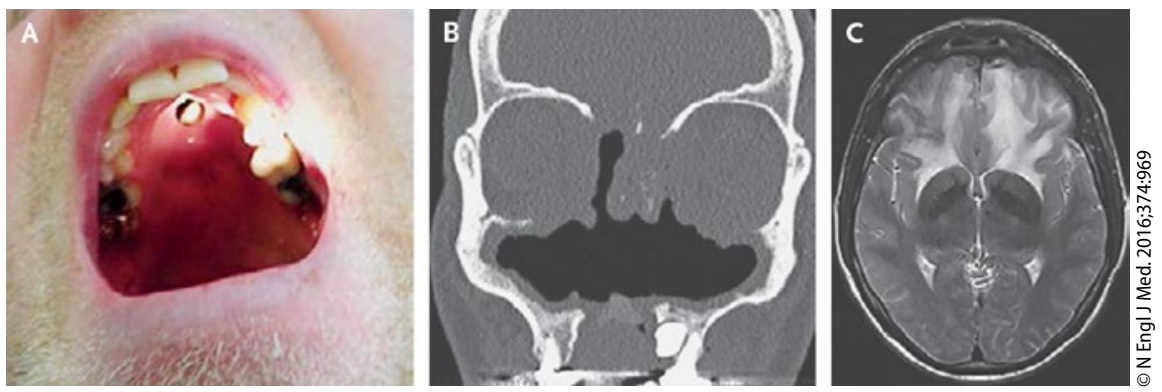

A: Defekt in der Mittellinie des harten Gaumens. B: Destruktionen der Nasenhöhle im CT. C: Ödem des Frontallappens im MRT (T2-Gewichtung).
(ANCA) im Serum. Der Liquorbefund war unauffällig, und in Biopsien aus dem Gewebedefekt wuchsen weder Bakterien noch Pilze.

Histologisch zeigte sich eine chronische Entzündung, die sowohl mit einem Kokain-Missbrauch wie auch einer Granulomatose mit Polyangiitis vereinbar war. Es bestanden allerdings keine weiteren bronchopneumonischen Läsionen, die für letztere Diagnose gesprochen hätten. Aufgrund der langjährigen Kokain-Anamnese erschien ein nekrotisierender entzündlicher Prozess durch den Kokain-Missbrauch wesentlich wahrscheinlicher. Die positiven ANCA können auch bei Kokain-induzierten Läsionen auftreten und verursachen differenzialdiagnostische Probleme. Die Be- handlungsmöglichkeiten sind sehr eingeschränkt und bestehen in einer Beendigung des Kokain-Abusus, einem Débridement des Defekts und ggf. der Behandlung einer bakteriellen Superinfektion. Immunsuppressiva spielen bei diesen Läsionen keine Rolle. Unter Drogenabstinenz schloss sich der Defekt am Gaumen langsam, es verblieb aber ein leichtes Frontalhirnsyndrom.

Prof. Dr. med. H. S. FüeßI

- Stelten BML, Post B (b.stelten@cwz.nl). Midline destructive lesions in a cocaine user

NEngl J Med. 2016;374:969 